\title{
Anesthesia in Patient with Lead Poisoning: Case Report
}

\author{
Luís Mauro Alvim de Lima ${ }^{1}$, Flávio Castro Resende ${ }^{2}$, Ana Carolina Janiques dos Santos ${ }^{2}$, \\ Patricia Pimentel Duarte Rodrigues Terra ${ }^{3}$, Alberto Vieira Pantoja, TSA 4 , \\ Marco Antonio Cardoso de Resende, TSA ${ }^{5}$
}

\begin{abstract}
Summary: Lima LMA, Resende FC, Terra PPDR, Santos ACJ, Pantoja AV, Resende MAC - Anesthesia in Patient with Lead Poisoning: Case Report.

Background and objectives: Lead poisoning, also Saturnism, results from chronic lead poisoning, common after occupational exposure. Projectiles retained in the body may result in increased levels of plasma lead with numerous clinical implications, particularly neurological. We report a case of a symptomatic patient, undiagnosed, whose diagnosis was made during the preanesthesia evaluation.
\end{abstract}

Case report: The patient was attended at our hospital to remove a bullet lodged in his left knee 14 years ago, presenting with polyneuropathy without investigation. During the preanesthetic visit, saturnism was hypothesized and confirmed by high plasma lead levels (129 $\mu$ g.dL-1). Surgery was performed under general anesthesia before starting lead chelation. During anesthesia, the patient developed apnea, without chest-wall rigidity after administration of fentanyl $(50 \mu \mathrm{g})$.

Conclusion: Lead poisoning interferes with the function of various organs and systems, alters oxidative metabolism and intracellular signaling mechanisms. Neurological involvement, with reduced neural conduction, deserves special attention from anesthesiologists.

Keywords: Anesthesia, General; Lead Poisoning; Toxicity Tests.

\section{INTRODUCTION}

Since ancient times, in excavations dating back to Troy (3000$2500 \mathrm{BC}$ ), there are traces of lead use for making weapons, but only with Hippocrates (370 BC), the first mention of poisoning occurred as a cramping pain. Aqueduct pipes and wine, in which lead was used as a preservative, were the main sources for poisoning in ancient Rome ${ }^{1}$. Saturnism in adults is most often a form of chronic lead poisoning which accumulation promotes neurological, gastrointestinal, hematopoietic, renal, musculoskeletal, and reproductive changes. Occupational exposure occurs in foundries, printing, production and recycling of batteries, ceramics, paints, crystals, and with the use of lead-based solders. Use of medications, ingestion of contaminated food or water, and the presence of a firearm

Received from Centro de Ensino e Treinamento/Sociedade Brasileira de Anestesiologia (CET/SBA), Department of Anesthesiology, Hospital Universitário Antonio Pedro (Huap), Universidade Federal Fluminense (UFF), Niterói, RJ, Brazil.

1. $\mathrm{ME}_{3}$, Centro de Ensino e Treinamento (CET/SBA), Hospital Universitário Antonio Pedro (Huap), Universidade Federal Fluminense (UFF)

2. Anesthesiologist, Huap-UFF

3. Anesthesiologist, Huap-UFF; Master in Pharmacology, (UFRJ)

4. Instructor, CET/SBA Huap-UFF

5. Co-responsible forCET/SBA Huap-UFF; Master in Neurology, (UFF)

Submitted on December 8, 2011.

Approved for publication on January 23, 2012.

Correspondence to:

Dr. Marco Antonio Cardoso de Resende

Hospital Universitário Antonio Pedro (Huap)

R. Marquês de Paraná 303, 3aa andar (Serviço de Anestesiologia)

24033-900 - Niterói, RJ, Brasil

E-mail:macresende@gmail.com projectile lodged in the bones, joints, or tissues are causes of occupational exposure ${ }^{2-4}$. Children are more susceptible to the toxic effects of lead for having the blood brain barrier and musculoskeletal system still under development; therefore, they present symptoms at lower concentrations $\left(<40 \mu \mathrm{g} \cdot \mathrm{dL}^{-1}\right)$ than those found in symptomatic adults $\left(40-60 \mu \mathrm{g} \cdot \mathrm{dL}^{-1}\right)^{5}$. Severe poisoning may present paresis or paralysis, nephropathy, encephalopathy, dark blue gum line, and intermittent abdominal cramps ${ }^{5}$. We report the case of a patient undergoing anesthesia to remove a firearm projectile lodged in his left knee 14 years ago.

\section{CASE REPORT}

Male patient, white, 43-year old, $50 \mathrm{~kg}, 1.68 \mathrm{~m}$, with complaints of pain and functional disability in his left knee, admitted for removal of a firearm projectile (Figure 1). During preanesthetic visit, the patient was pale, emaciated, and adynamic. He reported previous abdominal surgery with gastroenterostomy, cramping abdominal pain, anorexia, constipation, and sexual impotence. The patient made irregular use of analgesics and anti-inflammatory drugs. Physical examination revealed Mallampati I, good neck mobility, generalized muscle atrophy, decreased strength in the arms and bent wrists (Figure 2), in addition to severe difficulty walking. Tests showed red blood cells $(29 \%)$ and hemoglobin (9.6 g.dL-1), but urea, creatinine, glucose, electrolytes, and thyroid hormones values, chest $X-$ ray and electrocardiogram were normal. He was classified as ASA III, and neurological evaluation to elucidate his condition before the anesthetic procedure was recommended. Electro- 


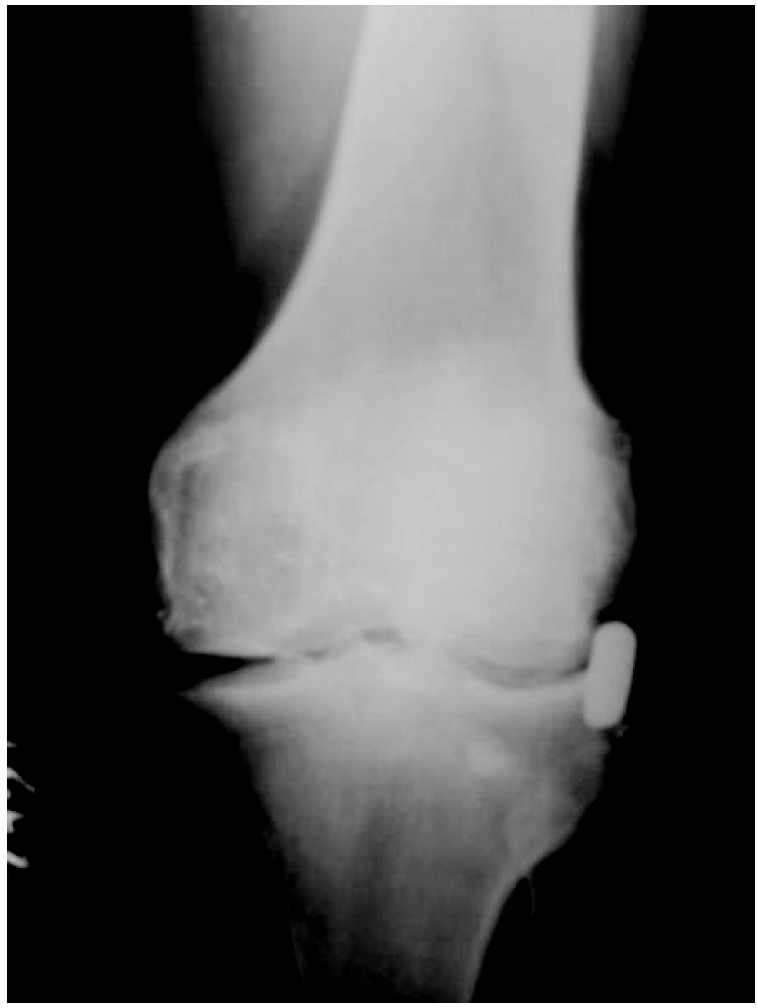

Figure 1.

myography was compatible with polyneuropathy, and lead plasma level was $129 \mu \mathrm{g} \cdot \mathrm{dL}^{-1}$ (reference, value $40 \mu \mathrm{g} \cdot \mathrm{dL}^{-1}$ ). After confirming the diagnosis saturnism, it was decided not to wait for chelation therapy. In the operating room, patient was monitored with ECG (DII and V5), noninvasive blood pressure, and pulse oximetry. Venipuncture was made in the left external jugular using a $16-\mathrm{G}$ catheter. After preoxygenation, he showed apnea with the slow intravenous administration of fentanyl $(50 \mu \mathrm{g})$, without chest-wall rigidity. Propofol $(100 \mu \mathrm{g})$ was infused and laryngeal mask No. 3 introduced without hemodynamic changes. Anesthesia was maintained with a vaporizer calibrated for isoflurane, in $\mathrm{CO}_{2}$ absorber system, VCV $=400 \mathrm{~mL}, 12 \mathrm{ipm}$, PEEP $=5 \mathrm{~cm} \mathrm{H} 2 \mathrm{O}, \mathrm{FGF}=2$ L. $\mathrm{min}^{-1}$ and $\mathrm{FiO}_{2}=0.4$, keeping $\mathrm{EtCO}_{2}$ between $30-35 \mathrm{~mm} \mathrm{Hg}$. Cefazolin $(1 \mathrm{~g})$, dipyrone $(1.5 \mathrm{~g})$, ondansetron $(4 \mu \mathrm{g})$, and Ringer's lactate $(800 \mathrm{~mL})$ were administered. The anesthesia progressed uneventfully in 75 minutes. At the end of procedure, laryngeal mask was removed, with ventilatory pattern and satisfactory analgesia.

\section{DISCUSSION}

Despite the high incidence of firearm-related accidents, McQuirter et al. ${ }^{2}$ estimated that less than 100 cases of lead toxicity caused by projectile lodged in the body have been reported in the literature until $2004^{2}$. Symptom onset is insidious, and high de-

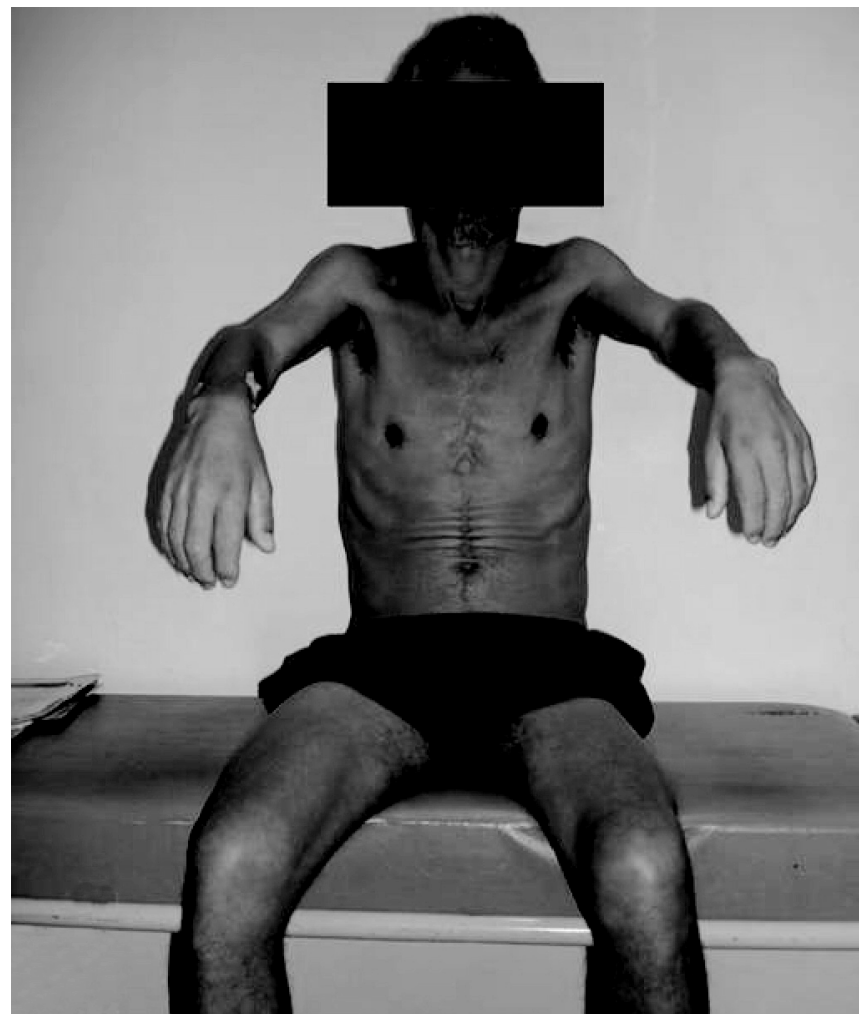

Figure 2.

gree of suspicion is required for diagnosis. Inorganic lead has its solubility affected by the medium $\mathrm{pH}$ in which it is located. Thus, projectiles lodged in alkaline media, such as synovial fluid, have increased absorption. In the synovium, lead can cause synovitis, joint deterioration, systemic absorption, and death, sometimes decades after the accident. The projectile location and its fragmentation with bone interface, in contact with the cerebrospinal fluid, synovial fluid, or pleural surface area, and duration of exposure are crucial for increased absorption and risk of toxicity ${ }^{6}$. In the body, bones are the main natural reservoir of lead.

Lead interferes competitively with divalent cations (calcium, magnesium, and zinc), impairs mitochondrial oxidative phosphorylation and intracellular signaling systems, causes neuroendocrine and smooth muscle contraction dysfunction ${ }^{7}$. Lead has a high affinity for sulfhydryl groups. Inhibition of three important enzyme of the heme biosynthesis- 5 delta-aminolevulinic acid dehydratase (ALA-D), coproporphyrinogen oxidase, and ferrochelatase-causes hematological changes. Anemia, typically hypochromic and microcytic with basophilic stippling of erythrocytes ${ }^{7}$, is a late complication ${ }^{8}$. Cramping abdominal pain, which may manifest as pseudoacute abdomen, and constipation are the most frequent gastrointestinal symptoms associated with decreased release of acetylcholine preganglionic and inhibition of $\mathrm{Na}^{+} \mathrm{K}^{+}$-ATPase, which affect the dynamics of water. Other symptoms may be present, such as nausea, vomiting, anorexia, and diarrhea. 
Lead accumulation in renal tubules characteristically causes interstitial nephritis. Childhood cognitive impairment, encephalopathy, and seizures may be caused by lead exposure ${ }^{8}$.

Preoperative evaluation revealed several nonspecific signs and symptoms suggestive of systemic disease, which led to delayed procedure. The presence of peripheral neuropathy in patients with intra-articular projectile increases the suspicion of lead toxicity. Diagnosis was established by the gold standard approach, measurement of venous blood lead concentration.

Saturnism treatment is done by chelation therapy to decrease plasma lead concentration and mobilize bone reservation. However, prevention is more important than treatment because it can reduce the overall amount of lead in the body, prevents increased plasma concentration and maintenance of slightly higher levels associated with cognitive deficits and lethargy. Thus, projectile removal should not be delayed as soon as one realizes the risk of systemic absorption, with the goal of reducing the amount absorbed ${ }^{9}$. In our report, although the lead levels were extremely high, it was considered safe to remove the projectile before starting chelation therapy, which was unavailable at that time.

The most striking sign of nervous system involvement in lead chronic toxicity is a decrease in nerve conduction, which evolves to peripheral neuropathy. Already in 1978, Valciukas et al. ${ }^{10}$ justified the occurrence of neuropathy by lead exposure, through the destruction of Schwann cells followed by segmental demyelination and secondary axonal degeneration, with disease progression ${ }^{10}$. There is selective impairment of motor nerves and forearm extensor muscle injury, with typical weakness and dropping hands, but with preserved sensitivity ${ }^{1,8}$. The clinical picture is confused, often presenting with carpal tunnel syndrome ${ }^{11}$. In view of confirmed polyneuropathy, there is less need for neuromuscular blocker and analgesics during anesthesia, in addition to risk of drug-induced respiratory depression. Our patient experienced great sensitivity after fentanyl administration, with apnea, which reaffirmed the need for tailored treatment, careful titration of anesthetic agents, and neuromuscular block monitoring. 


\section{REFERENCES}

1. Gracia RC,Snodgrass WR - Lead toxicity and chelation therapy. Am J Health Syst Pharm, 2007;1:45-53.

2. McQuirter JL, Rothenberg SJ, Dinkins GA et al. - Change in blood lead concentration up to 1 year after a gunshot wound with a retained bullet. Am J Epidemiol, 2004;7:683-692.

3. Sanborn MD, Abelsohn A, Campbell M et al. - Identifying and managing adverse environmental health effects: 3 . Lead exposure. CMAJ, 2002;10:1287-1292.

4. Akhtar AJ, Funnye AS, Akanno $\mathrm{J}$ - Gunshot-induced plumbism in an adult male. J Natl Med Assoc, 2003;10:986-990.

5. Dedeken P, Louw V, Vandooren AK et al. - Plumbism or lead intoxication mimicking an abdominal tumor. J Gen Intern Med, 2006;6:C1-3.

6. Coon T, Miller M, Shirazi F et al. - Lead toxicity in a 14-year-old female with retained bullet fragments. Pediatrics, 2006;1:227-230.

7. Riess ML, Halm JK - Lead poisoning in an adult: lead mobilization by pregnancy? J Gen Intern Med,2007;8:1212-5.

8. Moreira FR, Moreira JC - Effects of lead exposure on the human body and health implications. Rev Panam Salud Publica, 2004;2:119-129.

9. Chen A, Rhoads GG, Cai B et al. - The effect of chelation on blood pressure in lead-exposed children: a randomized study. Environ Health Perspect, 2006;4:579-583.

10. Valciukas JA, Lilis R, Fischbein A et al. - Central nervous system dysfunction due to lead exposure. Science, 1978;4354:465-467.

11. Araki S, Murata K,Yokoyama K - Assessment of central, peripheral, and autonomic nervous system functions in vibrating tool operators: neuroelectrophysiological studies. Environ Res, 1993;2:272-282. 